\title{
STUDENT PERCEPTIONS OF VIRTUAL REALITY IN HIGHER EDUCATION
}

\author{
Tebogo John Matome ${ }^{1}$ and Mmaki E. Jantjies ${ }^{2}$ \\ ${ }^{I}$ Master Student \\ ${ }^{2}$ Associate Professor \\ Department of Information Systems \\ University of the Western Cape, South Africa
}

\begin{abstract}
Continuous advancements in technology provide an opportunity for higher educational institutions to enhance the electronic learning experiences of students. Following a review of literature, this research explored student perceptions on the possible uses of virtual reality in their universities, as a way of easing their access to learning material. The research was conducted with the aim of answering the question of how virtual reality can be used to enhance learning, for higher learning institutions. Using a mixed-method research method, online surveys were distributed to registered university students in South Africa, using a simple random sampling strategy, to obtain a diverse and non-biased data set. The quantitative and qualitative responses were analyzed separately, before being triangulated, and used to inform the discussion and conclusion. Ultimately, the research found that although there are various benefits associated with the introduction of Virtual Reality - in South African Higher Education Institutions - the diverse population of participating students, and the varying differences in their socioeconomic statuses, would result in the inequitable distribution and usage of its resultant advantages.
\end{abstract}

\section{KEYWORDS}

Augmented Reality, e-Learning, Higher Education, Immersive Technologies, Online University Resources, Virtual Reality

\section{INTRODUCTION}

In recent years, higher education has been viewed as the key to influencing holistic development (both economic and social), in emerging markets. Matherly, Amin \& Al Nahyan (2017) highlight the positive correlation, between the level of investment put into improving the quality of higher education, and the resultant increase in a nation's economic growth; insinuating that the higher the quality of a country's education system, the better the life of the inhabitants of the said country. Lane \& Johnstone (2012) also makes mention of the ongoing "great brain race" between various countries. They accredit the intensity of the race to the different nations' realization of the role played by higher education, and the level of skilled human capital it produced, when attempting to influence innovation, and economic development.

It is undeniable that the introduction, and evolution of technology, has changed the way in which all industries operate. Accordingly, the education system has not been overlooked by the effects of digitization and globalization. Many have researched the integration of different advanced learning technologies within the higher education sector. These include the study of challenges and prospects of attaining an online higher education within a South African university (Letseka \& Pitsoe, 2014), the study of student perceptions regarding the implementation and use of virtual classrooms (Çakýroðlu, 2014), and using artificial intelligence techniques, to influence interactive and adaptive, online education systems (Almohammadi, Hagras, Alghazzawi \& Aldabbagh, 2017). Resultantly, the addition of technology, to education, has resulted in positive outcomes on various issues faced by the sector, over the years. Furthermore, Passig (2015) mentions how advanced educational technologies, with their advanced interfaces, generate an accelerated enhancement in a wide range of skills that the natural educational environment alone cannot account for.

However, it has also been found that the implementation of online learning technologies, are not easily always accessible to different demographic groups. Cohen, Bancilhon \& Grace (2017) stress that the realization of a digitally connected society is highly dependent on, and cannot be disassociated from, the need for social 
and economic inclusion. Thus, introducing advanced technologies requires an understanding of the student body context, especially if the electronic learning requirements will extend beyond the campus environment.

In terms of the study's population, South African higher education institutions can be viewed as the perfect research population for the implementation of new technologies. This is as a result of the nation rich historic background, socio-economic characteristics, and the presence of a digital divide within the country's different races and groupings. For that reason, the University of the Western Cape (UWC), was deemed an appropriate sample frame. Banda \& Peck (2015) describe UWC as a previously disadvantaged university, which was initially introduced for the 'Coloured' population in apartheid South Africa, but challenged the apartheid system; ultimately admitting students from a variety of races and ethnicities. The university has since made various strides in the learning and equitable education landscape, and is today a world-recognized institution. In 2016, UWC had a registered student population of 21796 pupils, with a diverse representation from different socio-economic and demographic backgrounds. When comparing UWC to other universities in South Africa, Banda \& Peck (2018) further highlight the existing demographic differences of the institution. They state this diversity in demographics as the reason for UWC being currently regarded as a "multiplex research site".

Nyahodza \& Higgs (2017) use statistics from a 2016 World Bank survey (which concludes that the lower half of South Africa's population account for a mere $8 \%$ of the country's income) - to support their argument that a majority of these individuals are unable to afford educational resources, which also include computers and an Internet access. Furthermore, a study by Hersh \& Mouroutsou (2015) identifies income and language as the primary factors, defining the access to learning technologies. This is important to note, in the context of South Africa, where the apartheid era has resulted in a long-lasting influence on economic disparity. Nevertheless, when considering the different technologies that can be used in higher education, Virtual Reality, amongst other emerging technologies, provides an opportunity to bridge the resource gap for students allowing them to gain experience in their learning outcome using technology. This can be especially useful in resource constrained environments. Lu, Li, Chen, Kim \& Serikawa (2018) describe virtual reality as a computer system-generated simulation, which creates a virtual environment that can be interacted with, in a realistic manner. Taking into account that traditional learning takes place in the form of real-time interactions between learners and facilitators, Çakýroðlu (2014) makes mention of the implementation of VR-created simulations and assessments, allowing facilitators (teachers and lecturers) to test a learner's ability to react to real-life scenarios, based on their course of learning. This also allows students in high-risk fields (such as surgeons and engineers) to immerse themselves in realistic simulations, without the risks associated with making mistakes during real life operations, as well as without having physical access to such resources. It is, nonetheless, also important to acknowledge the advantages and developments that may arise from the introduction of VR within education. For example, the growth in the popularity of Virtual Reality may be the driving force, facilitating an increase in access to local higher education, across the different socio-economic groups, of South Africa. These possible advantages provide a rational reasoning for the necessity of investigating a possible solution, to a better interaction with learning content, for registered students of South African higher education institutions.

\subsection{Research Questions \& Objectives}

Unterhalter et al. (2017) acknowledge that although the recent student protests in South Africa shine a light on access and funding problems, these protests are not isolated events. Furthermore, they expand on the notion that these events uncover deep-rooted challenges within the higher education system, stemming from an unresolved colonial legacy. One must therefore consider that, due to the large economic disparity amongst the different socio-economic brackets of South Africa, some students find it more difficult than others to access the higher education system as well as related resources. This research therefore aimed to investigate the main research question of, how can Virtual Reality be used, to enable access to learning resources for higher education students, in South Africa? This was supported by four research sub-questions, giving direction to the research, and ultimately satisfying predetermined objectives. The research delved into what the main factors, contributing to the lack of access to Higher Education in South Africa, are, before a further reviewing past literature to answer the question of what Virtual Reality solutions have already been implemented, in higher education, across the world. Thirdly, the research investigated How a VR-augmented higher education system, affects a diverse student population, before the final research question aimed to identify the different ways in which VR can be used to support students' equitable access to higher education learning content. 
The sub-questions will help to satisfy the following objectives, and ultimately answer the primary research. The first objective being to identify the main forms of virtual reality, which have been used to support education in universities. Secondly, the research aimed to determine how VR can be used to support students, in order to adequately and less-effortlessly interacting with their institution's learning content. The final objective was to analyze the effects, as well as other advantages, of introducing a VR-augmented higher education system, within a diverse student population.

\section{LITERATURE REVIEW}

\subsection{Technology in Higher Education}

With the advent of technology, higher education qualifications have become more revered than in before. So much so that various countries have invested heavily in improving the quality of higher education, as it directly correlates to a nation's economic development (Matherly, Amin \& Nahyan, 2017). Matherly, Amin \& Nahyan (2017) identified an increase in salaries, enhanced employment opportunities, better mobility, a longer life expectancy, and an improved quality of life as some of the direct benefits of higher education qualifications. This supports to the notion that the importance of university or higher education is ever increasing, in an increasingly competitive global economy. Winters (2011) further notes that the main indicators and influence on a nation's human capital capability, is the presence of HE institutions in the area of dwelling.

However, in order to gauge the success of implementing technology in higher education, one must understand the knowledge and associated challenges of the technologies' primary users. These users include higher education students, as well as the teachers (and lecturers) of institutions. Jantjies \& Joy (2016) highlight the cultural and linguistic diversity of students, as a pivotal factor in the introduction of technology, in education system of South Africa. This is a result of the relatively large number of official languages and cultures recognized in the country, compared to other nations. It is, also important to consider the readiness and willingness of students, to accept the introduction of technology-aided learning. Chaka \& Govender (2017) found that Nigerian higher education learners were receptive to the idea of a technology-aided learning systems, with their perceptions of technology driving this acceptance rate. One can therefore assume that, should South African learners have similar perceptions of technology, the adoption of a blended learning system would result in a successful implementation. A Western Cape based study, by Chigona, Chigona \& Davids (2014), investigated the factors motivating educators to use ICTs in the province's disadvantaged areas. These factors were identified as the individual expectations of, the resultant feeling of achievement from, and the responsibilities associated with the use of ICTs in the aforementioned areas. As a result, this clarifies the need to motivate, inspire, and train educators on the use of ICTs in South African institutions.

\subsection{Introducing Virtual Reality in Higher Education}

Virtual reality enables the simulation of virtual environments through software applications to mimic the real-world environment. Hardware enabling users to gain access to virtual reality applications are either head mounted gear such as the oculus rift and the HTC Vive, or mobile devices supported through a head mounted casing. As VR hardware becomes more affordable, educational institutions are finding ways to enhance learning by supporting the immersive learning experience afforded by VR (Duta et al., 2011; Freina and Ott, 2015). Furthermore, a CAVE (Cave Automatic Virtual Environment) which is a 4 or 5 screened cube "room" can be used to allow between 2 to 8 participants to get an immersive 3D experience of a learning task.

A CAVE projects on the surrounding screens allowing surrounding 3D visuals of the content being projected. It is also supported by surround sound (Leder et al., 2019). While CAVES usually entail high implementation costs, they in turn provide simultaneous access to multiple students, as more than two students can use a CAVE at once. While there is a growing number of accessible VR hardware, there is a need for more developments of contextual and multilingual applications for various study fields. Many of the existing learning applications such as DentSim designed to support restorative dentistry education and The Geneva System developed to teach dental anatomy (Duta et al., 2011) were developed for a specific context. This provides an opportunity for African universities to develop applications which are specific to their fields as well considering contextual issues such as availability of content in multiple languages. 
However, it is also important to acknowledge that with the advances in technology, there are various high-powered applications of virtual reality, which have been implemented within the modern-day higher education curricula. For example, Al Awadhi, et al. (2018) make mention of the Titan of Spare application, which immerses students into a virtual realm of the solar system, allowing them to discover and better study the solar system's planets, from the comfort of their lecture halls. King, Tee, Falconer, Angell, Holly \& Mills (2018) also elaborate on the CILVRS (Collaborative Immersive Learning Virtual Reality Series) project of Bournemouth University, in the United Kingdom. This simulation, in which medical students take on the role of a medical practitioner, awaiting the arrival of their patient, provides students with the opportunity to learn from their mistakes (virtually) without jeopardizing the wellbeing of real patients.

\section{RESEARCH METHODOLOGY}

\subsection{Design \& Methodology}

A mixed method survey, which is described by Creswell \& Plano Clark (2007) as the use of both qualitative and quantitative data sourcing, in a single study, was used to conduct this study. A self-administered questionnaire, which was development and loosely guided by the 13 principles of questionnaire construction, was made available to the student population, using a simple random sampling approach. Responses from eighty-one $(\mathrm{N}=81)$ registered students, completed the survey. The data was analyzed using a thematic approach, described by Clarke \& Braun (2016) as the identification and analysis of responses, in order to deduce substantial patterns within a qualitative data set, ultimately classifying them as themes. The formulation of themes from the data, gave the researcher an opportunity to identify patterns and similarities in the students' responses, by finding commonalities in the problems identified, as well as the suggestions provided.

The identified themes, discussed in the research findings are: - 1) Student Access to Different content platforms, provided by the institution, 2) Student Usage and Knowledge of Technologies in Higher Education, and 3) Students' perceptions of a Virtual Reality Augmented in Higher Education System.

The first two themes allowed the for a better understanding of the third research sub-question, regarding How a VR-augmented higher education system would affect a diverse student population. In the first theme, we sought to understand the current experiences of online learning for students. Furthermore, the third theme was formulated to unpack the fourth research sub-question, which aimed to elaborate on the different ways in which VR can be used to support students' equitable access to higher education learning content.

The use and analysis of both qualitative and quantitative methods also allowed for the neutralizing of the weaknesses in one method, by using the strengths of the other method. However, a mixed method analysis also allows a researcher to enhance the strengths of one method, with the strengths of the other (Creswell, 2009). Furthermore, Tobergte (2013) describes triangulation as the effort of combining both types of data that have been used within the mixed method process, in the attempt to use one set to corroborate the other. As a result of the triangulation, the trends found within the qualitative analysis were used to try and provide a sense of justification/context to the trends found within the different themes of the qualitative data.

\section{FINDINGS}

\subsection{Access to Different Content Platforms, Provided by the Institution}

In this the theme, the study sought to understand the current digital learning devices and resources, which the students' access, and can be used to support VR. While the university provided full Internet access to students and staff, $26 \%$ of participants stated that the main issue they faced with Internet access, was the challenges of a periodic slow Internet connection. Other reasons stated included the lack of access to substantive online journal article portals, with nine percent highlighting this as a challenge to them. $16 \%$ of the participants reflected on the inability to access the institution's online student portal (Learning Management Systems) and learning platform, at certain times of the day, due to high usage. Almost half of the students at displayed in Figure 1 did not experience problems when accessing current online learning resources, as the campus had a good network support as well as technician and e-learning walk-in support centers. To understand how VR 
will be accessed by the student population, the research investigated the types of devices used, to access learning content. Table 1 reflects that almost two-thirds of the students accessed technology on campus and relied on the university computer labs. This provides a reflection on the type of VR applications, as well as tasks, that could be given to students.

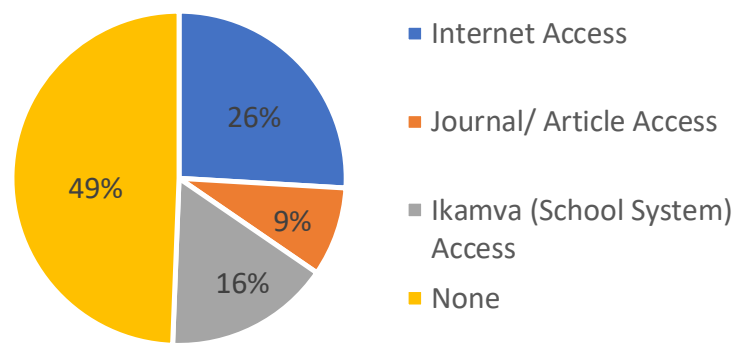

Figure 1. Problems faced when accessing online learning content

Table 1. Access to learning platforms on and off campus

\begin{tabular}{|l|l|l|l|l|l|}
\hline \multicolumn{2}{|c|}{} & Desktop & Mobile & Tablet & Total \\
\hline \multirow{2}{*}{ Residence } & Off Campus & 14 & 6 & 2 & 22 \\
\cline { 2 - 6 } & On Campus & 47 & 11 & 1 & 59 \\
\hline Total & 61 & 17 & 3 & $\mathbf{8 1}$ \\
\hline
\end{tabular}

\subsection{Student Usage and Knowledge of Technologies in Higher Education}

This theme sought to understand the different platforms used by students to interact with their course content. In Figure 2, 16\% of participants stated that their most used applications were Microsoft Office Suite or similar software. Further followed by a $20 \%$ use of Email, the institution's Online Library, and the university student Learning Management System services, respectively. Furthermore, 20\% of students reflected not having had any use of technology in their learning process. Contrastingly, $8 \%$ of students perceived the current technology infrastructure in the institution as being either unsatisfactory or mediocre. In aiming to understand student's current knowledge and use of virtual reality technology, the study also found that more than $60 \%$ of the students have neither knowledge of, nor experience with, virtual reality. However, $12 \%$ of the students did state that they had experienced virtual reality, with participants highlighting their knowledge for its use in gaming. Additionally, $26 \%$ of the students also stated that they only had some knowledge of virtual reality, but had no previous interaction with it. The students reflected that this knowledge of Virtual Reality was gained from either self-study, or first year Information Systems lectures. The results in the study reflected on the student population's lack of previous interaction with any VR applications, especially in the learning context. VR was often known to them as a gaming tool. The results also reflected the importance of students' training support for virtual reality, as a small percentage of them were currently not expected to use technology in their tasks. 


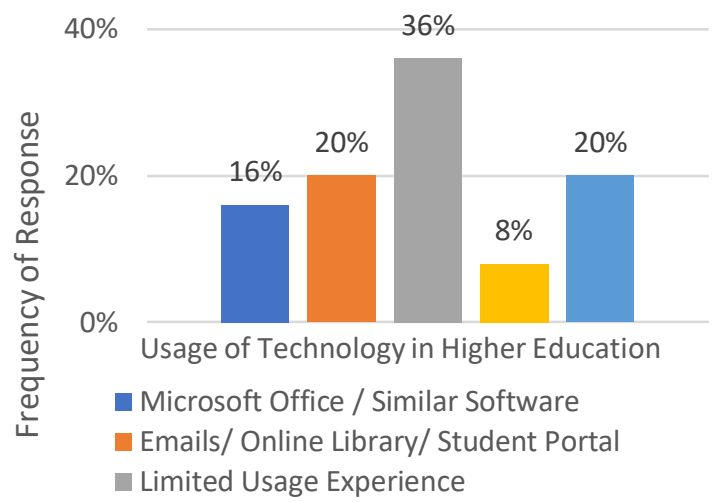

Figure 2. Participant usage of Technology in Higher Education

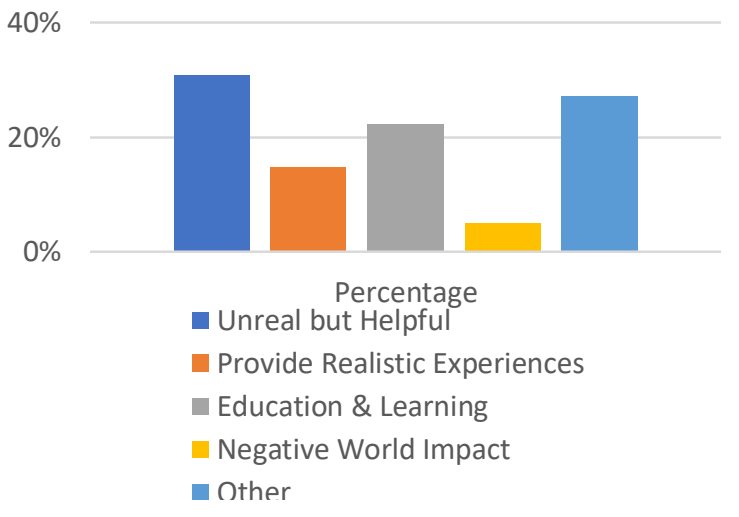

Figure 3. Student expectations of the introduction of virtual reality

\subsection{Students Expectations of a VR-Augmented Higher Education System}

Regarding what students would expect from a VR supported digital learning system, the results in Figure 3 reflect that $15 \%$ of students expected VR to provide them with realistic experiences of learning. Examples of these realistic experiences included visiting nature reserves or foreign destinations, from the comfort of their home. Five percent of the students expect that a VR supported learning experience will have a negative impact on their learning experience. Just over a fifth of the students expect VR to aid in education and learning capabilities of the population, both in formal institutions as well as through private/individual use.

Regarding students' perceptions on the advantages of integrating VR within Higher education, as reflected in Figure 4 below, the study found that while $22 \%$ of the respondents were unable to find any advantages of VR in their education, $20 \%$ of the students stated that it would afford them the opportunity of practical experience, as opposed to relying solely on the theory they are taught. A further $19 \%$ identified a possible increase in their learning and knowledge retention process, with $15 \%$ perceiving this innovation as one that will increase interaction between students, as well as lecturers. $10 \%$ of the students believe that the ability to access and better interact with course content, when not on the university campus will be the greatest advantage of implementing VR. Additionally, the remaining 16\% of respondents highlight an increased interaction with course content as the main advantage associated with a VR-augmented Higher Education system.

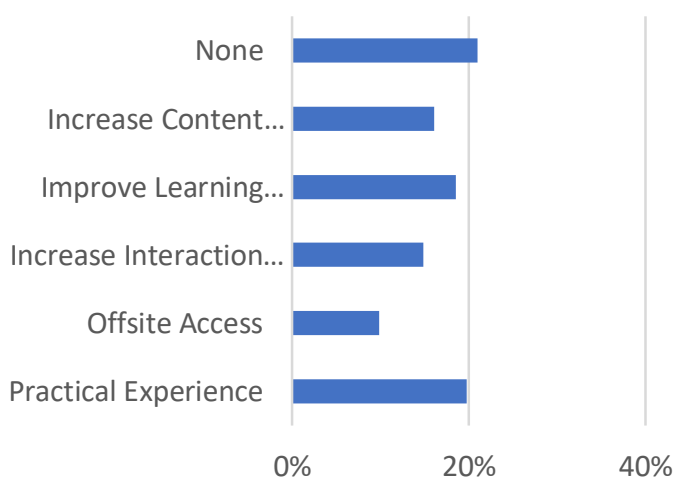

Figure 4. Student's perceived advantages of Virtual Reality in Higher Education

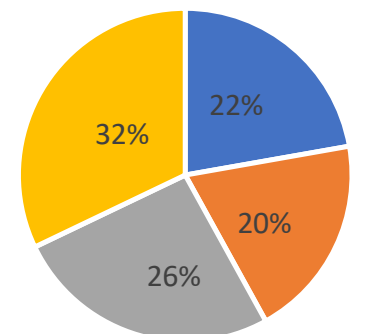

- Slow Integration into Course Curriculum

- Educate Students on VR Use

- Provide VR Labs/Infrastructure on Campus

none

Figure 5. Student Suggestions on How to Make VR implementation Inclusive to All Students

In terms of the different ways that students believe the implementation of VR can be made inclusive, the following findings were recorded. In Figure 5, 22\% of student believe that slowly integrating the technology into their curriculum, would be the best way to influence equitable use of the technology. However, while a fifth of the respondents highlight the necessity of educating students on the effective use of VR in higher education, a quarter of the respondents felt that the best way to promote equitable access to the technology is through the building and provision of VR-dedicated labs (and infrastructure), on their campus. 


\section{DISCUSSION}

One aspect of the research aimed to find the main issues faced by students, when interacting with the different online platforms, of their institution. This was analyzed within the theme of Student Access to Different content platforms, provided by the institution. The most prevalent issues were the lack of access to a stable internet connection, as well as the inability to access their online learning management system during certain periods of the day. Resultantly, with institutions having a limited number of computer labs (and computers), compared to the overall student population, most students would be required to use personal computers and laptops to interact with their online content. If taken in the context of Nyahodza \& Higgs (2017) - who stated that a large fraction of South African students are unable to afford educational resources, such as personal computers - this lack of access to a workspace, and adequate internet connection poses a challenge to VR, within higher education learning. In cases where students do not own smart phones, the lecturers would be expected to provide VR platforms or provide alternative solutions, which consider the resources that students have access to. Dedicated VR supportive labs or access to mobile devices, smart phones or a CAVE would be important in ensuring that students can effectively access and use VR in their education. The results also reflected the importance of the existing e-learning center to support VR systems training support which was currently effective in supporting other e-learning training services.

Regarding the theme of "Student Usage and Knowledge of Technologies in Higher Education" the study reflected that many of the students residing on-campus make use of the institution's Wi-Fi services, and thus mainly relied on the university network services. Furthermore, students residing off-campus would be required to carry the cost of an increase in the bandwidth required to efficiently use VR. The role of free Wi-Fi in supporting current e-learning activities reflected the importance of VR software which was also available offline. The study further reflected that academics using VR should be considerate of the role of the Internet in the e-learning process, and thus cannot solely rely on VR applications requiring access to the Internet, especially with tasks required beyond the lecturer room (Blignaut, Els \& Howie, 2010). Furthermore, with a combined total of $56 \%$ of students having reported that they had either limited, or no, experience with technology usage in higher education, this reflected on literature by Walker \& Mkwananzi (2015), highlighting that students that are enrolled in higher education institutions, filter in from positions of extreme inequality. When discussed in conjunction with other findings, where $60 \%$ of the students reported that they had no knowledge or experience of virtual reality, extensive training and education on the usage of the VR technology was found to be important in its successful implementation.

When investigating the theme of "Students' expectations of a Virtual Reality-Augmented Higher Education System", many of the participants had no prior knowledge of VR and its use in education. With regards to the advantages expected from a VR-augmented Higher Education, a combined 26\% of the respondents cited perceived advantages in possible interaction and collaboration between students, as well as with lectures, as a result of better accessibility and interaction with course content. This realization correlated with Viberg \& Grönlund (2013), who stated that the introduction of VR would change the traditional delivery of, and access to, learning content; by overcoming the spatial-temporal characteristic of modern-day formal education. Furthermore, Viberg \& Grönlund (2013) also made mention of the advancements afforded by VR, resulting in habitual online meetings and classrooms, as well as the opportunity to integrate mobile learning into curricula, to further overcome these spatial-temporal factors. Considering the increase in mobile technology adoption (relative to that of personal computers) in developing countries, with mobiles being identified as the second largest platform usage for accessing online learning content - tailoring the introduction of VR to a more mobile-based platform would deliver the most benefits, and a greater realization of the aforementioned advantages.

In terms of promoting inclusivity of, and equitable access to, virtual reality in the higher education system, the findings identified the need for dedicated virtual reality labs and infrastructure (provided by the institution) as being the most imperative factor to widespread adoption and usage. In reference to Letseka \& Pitsoe (2014) who stated that education delivery models of global institutions is moving towards one that is cost-effective, while not foregoing service quality, this finding would highlight the need for South African institutions to transition towards integrating and procuring emerging technologies, within their respective campuses. The findings reflect on the notion of Hersh \& Mouroutsou (2015) who state the main hindrances of access to these emerging technologies include the cost off lack of funding for maintenance of emerging technologies, as well as a need for training and support for academics. Future use of VR application in higher education could thus enhance learning effectively through both infrastructure and human resource support to ensure its success. 


\section{CONCLUSION}

Conclusively, although there has been an increase in the implementation of virtual reality technologies, within the global education system; it is important to note that this increase is predominantly in the institutions of developed nations. This may be due to cost of infrastructure associated with VR technology being relatively high, in comparison to other technologies that are currently being used in institutions. Furthermore, with the financial, procurement and quality-related challenges - faced by the South Africa government, as well as some higher education institutions - the introduction of Virtual Reality, in the nation's current economic climate, would more of a burden, than an advantage to all parties with a vested interest. However, even with the challenges of introducing this technology, there is indeed a plethora of benefits that can be realized.

In addition to increasing the accessibility of online interaction with an institution's learning content, as well as providing practical experience and knowledge of one's respective field of study; a relationship between VR and higher education will provide facilitators with increased avenues of disseminating and assessing course-related content, in a way that will be easier to remember, for the students. Nevertheless, the training of VR-usage for such a diverse student population, from various backgrounds, may be further complicated by other technology adoption factors. With the data and internet, prices of South Africa being identified as one the most expensive in the world (in comparison to other developing countries) the bandwidth-heavy nature of VR usage would limit the holistic adoption of the technology across the entire student population. Another notable aspect of the study would be the consideration of the limitations surrounding the study. These limitations, in one way or another, may have had an influence on the outcome of the study; and could be mitigated in future research.

The first limitation is the duration of the study, which was conducted over a period of seven months. Another limitation would be the location of the study. With the study being conducted solely in the University of the Western Cape, it would be difficult to generalize the study to the rest of South Africa's higher learning institutions, as they each have a different demographic profile, respectively. This study, with consideration of the above limitations, has served as an investigation of the effects of VR in a higher education institution, in the Western Cape. Furthermore, the results of the study can be further researched, on a larger scale, and over a longer time period; to better investigate the trends suggested within this article. Overall, although the benefits associated with the introduction of VR within the South African higher education system will provide new and enhanced opportunities, when accessing and interacting with one's online course material, the financial requirements of such an implementation for both institutions, and students, would not promote an equitable distribution and adoption of the technology. Resultantly, the access to VR augmented online learning content will only be beneficial to primarily those of the upper socioeconomic brackets of the nation.

\section{REFERENCES}

Almohammadi, Khalid, Hani Hagras, and Daniyal Alghazzawi. 2017. "A Survey of Artificial Intelligence Techniques Employed for Adaptive Educational Systems within E-Learning Platforms.” Journal of Artificial Intelligence and Soft Computing Research 7 (1): 47-64. https://doi.org/10.1515/jaiscr-2017-0004.

Awadhi, Shouq Al, Noor Al Habib, Dalal Al-Murad, Fajer Al deei, Mariam Al Houti, Taha Beyrouthy, and Samer Al-kork. 2018. "Interactive Virtual Reality Educational Application" 3 (4): 72-82.

Banda, Felix, and Amiena Peck. 2016. "Diversity and Contested Social Identities in Multilingual and Multicultural Contexts of the University of the Western Cape, South Africa." Journal of Multilingual and Multicultural Development 37 (6): 576-88. https://doi.org/10.1080/01434632.2015.1106547.

Blignaut, Seugnet, Christo Els, and Sarah Howie. 2010. “Contextualizing South Africa's Participation in the SITES 2006 Module." South African Journal of Education 30 (October 2004): 555-70.

Cakiroglu, Unal. 2014. "Evaluating Students' Perspectives about Virtual Classrooms with Regard to Seven Principles of Good Practice." South African Journal of Education 34 (2): 1-19. https://doi.org/10.15700/201412071201.

Chaka, John Gyang, and Irene Govender. 2017. “Students' Perceptions and Readiness towards Mobile Learning in Colleges of Education: A Nigerian Perspective." South African Journal of Education 37 (1): 1-12.

Chigona, Agnes, Wallace Chigona, and Zane Davids. 2014. "Educators' Motivation on Integration of ICTs into Pedagogy: Case of Disadvantaged Areas." South African Journal of Education 34 (3): 1-8. https://doi.org/10.15700/201409161051.

Clarke, Victoria, and Virginia Braun. 2017. "Thematic Analysis." Journal of Positive Psychology. https://doi.org/10.1080/17439760.2016.1262613. 
Cohen, Jason, Jean Marie Bancilhon, and Thomas Grace. 2018. "Digitally Connected Living and Quality of Life: An Analysis of the Gauteng City-Region, South Africa." Electronic Journal of Information Systems in Developing Countries 84 (1): 1-12. https://doi.org/10.1002/isd2.12010.

Creswell, J.W., \& Plano Clark, V.L. (2007). Designing and conducting Mixed Methods Research. USA. Sage Publications.

Creswell, John W. 2009. Research Design: Qualitative, Quantitative, and Mixed Methods Approaches. 4th ed. California: Sage. http://www.ceil-conicet.gov.ar/wp-content/uploads/2015/10/Creswell-Cap-10.pdf.

Dutã, Mihaela, Corneliu I Amariei, Crenguta M Bogdan, Dorin M Popovici, Nicolae Ionescu, and Cristina I Nuca. 2011. "An Overview of Virtual and Augmented Reality in Dental Education." Journal of Oral Health and Dental Management 10

$42-49$. http://scholar.google.co.za/scholar_url?url=https://pdfs.semanticscholar.org/0ca2/e4b2aa03f327ec58f496e56116ed27 bfedc9.pdf\&hl=en\&sa=X\&scisig=AAGBfm14jb5sJYvMpVkNBlcPwMC4XdF7nw\&nossl=1\&oi=scholarr.

Freina, Laura, and Michela Ott. 2015. "A Literature Review on Immersive Virtual Reality in Education: State of The Art and Perspectives." In ELearning and Software for Education (ELSE). Romania. https://www.researchgate.net/publication/280566372_A_Literature_Review_on_Immersive_Virtual_Reality_in_Edu cation_State_Of_The_Art_and_Perspectives.

Hersh, M. A., and S. Mouroutsou. 2015. "Learning Technology and Disability: Overcoming Barriers to Inclusion: Evidence from a Multi-Country Study.” IFAC-PapersOnLine 48 (24): 83-88. https://doi.org/10.1016/j.ifacol.2015.12.061.

Jantjies, Mmaki, and Mike Joy. 2016. "Lessons Learnt from Teachers' Perspectives on Mobile Learning in South Africa with Cultural and Linguistic Constraints." South African Journal of Education 36 (3): 1-10. https://doi.org/10.15700/saje.v36n3a1274.

King, Denyse, Stephen Tee, Liz Falconer, Catherine Angell, Debbie Holley, and Anne Mills. 2018. "Virtual Health Education: Scaling Practice to Transform Student Learning." Nurse Education Today 71 (December): 7-9. https://doi.org/10.1016/j.nedt.2018.08.002.

Lane, J.E., Johnstone, D.B. (Eds.). (2012). Universities and Colleges as Economic Drivers: Measuring Higher Education's Role in Economic Development. State University of New York Press.

Leder, J., Horlitz, T., Puschmann, P., Wittstock, V. and Schütz, A., (2019). Comparing immersive virtual reality and powerpoint as methods for delivering safety training: impacts on risk perception, learning, and decision making. Safety science, 111, pp.271-286.

Letseka, Moeketsi, and Victor Pitsoe. 2014. "The Challenges and Prospects of Access to Higher Education at UNISA." Studies in Higher Education 39 (10): 1942-54. https://doi.org/10.1080/03075079.2013.823933.

Lu, Huimin, Yujie Li, Min Chen, Hyoungseop Kim, and Seiichi Serikawa. 2018. "Brain Intelligence: Go beyond Artificial Intelligence." Mobile Networks and Applications 23 (2): 368-75. https://doi.org/10.1007/s11036-017-0932-8.

Matherly, Laura L., Nadia Amin, and Shamma Sultan Khalifa Al Nahyan. 2017. "The Impact of Generation and Socioeconomic Status on the Value of Higher Education in the UAE: A Longitudinal Study." International Journal of Educational Development 55 (May): 1-10. https://doi.org/10.1016/j.ijedudev.2017.04.002.

Nyahodza, Lena, and Richard Higgs. 2017. "Towards Bridging the Digital Divide in Post-Apartheid South Africa: A Case of a Historically Disadvantaged University in Cape Town." South African Journal of Libraries and Information Science 83 (1): 39-48. https://doi.org/10.7553/83-1-1645.

Passig, David. 2015. "Revisiting the Flynn Effect through 3D Immersive Virtual Reality (IVR)." Computers and Education 88: 327-42. https://doi.org/10.1016/j.compedu.2015.05.008.

Tobergte, David R., and Shirley Curtis. 2013. "Social Research Methods." Journal of Chemical Information and Modelling 53 (9): 1689-99. https://doi.org/10.1017/CBO9781107415324.004.

Unterhalter, Elaine, Stephanie Allais, Colleen Howell, Tristan McCowan, Louise Morley, Ibrahim Oanda, and Moses Oketch. 2018. "Conceptualising Higher Education and the Public Good in Ghana, Kenya, Nigeria, and South Africa." Conference: Comparative and International Education Society (CIES), no. March: 1-32. http://discovery.ucl.ac.uk/10050089/.

Viberg, Olga, and Åke Grönlund. 2013. “Computers \& Education Cross-Cultural Analysis of Users' Attitudes toward the Use of Mobile Devices in Second and Foreign Language Learning in Higher Education: A Case from Sweden and China.” Computers \& Education 69: 169-80. https://doi.org/10.1016/j.compedu.2013.07.014 .

Walker, Melanie, and Faith Mkwananzi. 2015. "Challenges in Accessing Higher Education: A Case Study of Marginalised Young People in One South African Informal Settlement.” International Journal of Educational Development 40: 40-49. https://doi.org/10.1016/j.ijedudev.2014.11.010.

Winters, John V. 2011. "Human Capital, Higher Education Institutions, and Quality of Life.” Regional Science and Urban Economics 41 (5): 446-54. https://doi.org/10.1016/j.regsciurbeco.2011.03.001.

Youngblut, Christine. 1998. "Educational Uses of Virtual Reality Technology." Institute for Defense Analysis, no. January. http://papers.cumincad.org/data/works/att/94ea.content.pdf. 